\title{
Association of Chemical stress with Type I \& II diabetes
}

Shamoon noushad, Hamza Akhtar, Safdar Ali, Zafar Iqbal Abbassi, Sadaf Ahmed, Soobhi Mehdi, Kaneez Fatima \& Samina Saleem

Advance Educational Institute \& Research Centre

Shaheed Motharma Benazir Bhutto Medical College Layari

Koohi Goth Women Hospital

Patel Hospital

Baqai Medical University

Corresponding author: Shamoon@aeirc-edu.com

\begin{abstract}
Abstrac
Background Diabetes mellitus is characterized by absolute or relative deficiencies in insulin secretion or insulin action correlated with chronic hyperglycemia and other disturbances in carbohydrate, lipid and protein metabolism results in weakening immunity. In addition, various biochemical disorders associated with diabetic vascular complications, such as hyperlipidemia and oxidative stress frequently co-exist with diabetes mellitus. Previous studies have also suggested that these and additional factors might involve with increasing chemical stress in diabetic patients. Material and methods The questionnaire based survey was conducted including both close \& open ended questions along with the assessment of chemical stress using Sadaf Stress Scale (SSS) version 2 among diabetic patients. This study was conducted in tertiary care hospitals of Karachi from October 1st till November 10th, 2014. Data was analyzed and plotted using SPSS version 20.0. Results This study showed that $28 \%$ of diabetic patients were in severe chemical stress. However, the various symptoms of severity included body temperature alterations (50\%), feeling of dehydration $(56 \%)$ and shortness of breath $(63 \%)$ were obtained. Conclusion It is concluded that the diabetes patient with type 2 diabetes are at higher risk of developing chemical stress that may indicate multiple metabolic and as indicated by prominent symptoms that can be a oxidative alterations on sequence of increase use of medications and altered glucose metabolism.
\end{abstract}

\section{Introduction}

In both developed and developing countries the prevalence of diabetes is growing at very significant rate which is a point of concern and burden to the health of the community (Wild S, Roglic $\mathrm{G}, 2004)$. Diabetes is a complex metabolic disorder characterized by defects in the body's ability to control glucose and insulin homeostasis (Justin L. Rains and Sushil K. Jain, 2011). According to International diabetes federation (IDF) 387 million people in the world have diabetes and more than 37 million people in the Middle-east and North Africa (MENA) Region whichwill rise to 68 million by 2035 . Pakistan is one of 20 countries of the IDF MENA region and there were 6.9 million reported cases of diabetes in Pakistan in 2014 and if current trend continues in adults (20-79 years) prevalence of diabetes will increase up to $6.8 \%$ (International Diabetes Federation, 2014)

Diabetes mellitus, especially type- 2 diabetes, is a public health problem which has reached epidemic proportions due to the rapidly increasing rates of this disease worldwide. Type 2 diabetes accounts for more than $90 \%$ of individuals diagnosed with diabetes (Wright E, 2006).

Diabetes affects many different organ systems in the body and, over time leads to serious complications.Several studies have shown that elevated extra and intra cellular glucose concentration result in oxidative stress which was proved in both experimental diabetes patients and animals (West IC 2000; Sayed MR 2011; Agnieszka P 2011).The etiology of oxidative stress in diabetes arises from a variety of mechanisms such as excessive oxygen radical production from auto-oxidation of glucose, glycated proteins, and glycation of anti-oxidative enzymes (Wolff SP, 1993) which limit their capacity to detoxify oxygen radicals and leads to oxidative stress (Giugliano D, 1995).

Oxidative stress and other indications of diabetes related complications may refer to chemical stress buildup by the increase amount of radicals and by products of metabolism as well as drug reactions. Chemical stress is either endogenous or exogenous. Endogenous means that we create them inside our bodies they are the result of improper diet or improper food combining while toxins from outside of the body are referred to as exogenous these are chemicals like food additives, pollution and drugs. Both endogenous or exogenous have the ability to reduce bodily ability to cope with environmental changes and cause damage or irritation to vital organs and sensitive tissues these sort of forces are responsible to induce chemical stress which can be a marker to identify substance induced potential damage to tissues (Sadaf, A. $\&$ Shamoon, N, 2013). All the changes ranges from providing fuel specifically maintain glucose levels can contribute to Chemical stress, directly or indirectly the inadequate nutrition or malnutrition can be a source of chronic stress. The individual responses many vary ongoing challenge that may be complicated by the impact of continued stress. Excessive stress is a major barrier to effective glucose control and a danger to one's general health. The last decade, demonstrating a handy association between altered metabolism and chemical stress. The integration of metabolism and effects on body, which under normal conditions is beneficial for the maintenance of good health, can become deleterious under conditions of metabolic challenge, as exemplified in diabetic patients.

There is a wide spread understanding of diabetes and stress separately but in present study we hypothesized that diabetics have a very specific share of stress induced by metabolic alteration and substance chronic use that is affecting bodily function chemically as distress. The HPA axis play a key role in deteriorating the tissue responses as the level of cortisol remain elevated for prolonged period of time lead the individual towards abnormal $\mathrm{CHO}$, fat and protein metabolism. Stress related counter regulatory hormone activity further aggravate this metabolic disturbance that has already been developed.

\section{Methods}

A cross sectional study was conducted among the diabetes patients in tertiary care hospital of Karachi from October 1st till November 10 th, 2014 . The patients of both the sexes Male $n=43(71.6 \%)$ and female $n=17(28.3)$ ranging from 15 to 41 years were included in the study. This questionnaire based survey included both close and open ended questions along with the assessment of chemical stress using Sadaf Stress Scale (SSS) version 2.0 among diabetes patients. This study included both type 1 and type 2 diabetes patients while gestational diabetes was excluded from the study. Data was analyzed, calculated and plotted using SPSS version 20.0 . 
Table 1: Symptoms of Chemical stress in diabetic Patients

\begin{tabular}{|l|c|c|c|c|c|c|}
\hline & SYMPTOMS & NEVER & RARELY & SOMETIMES & VERY OFTEN & ALWAYS \\
\hline 1 & Like cozy rooms (deoxygenated places)? & $15 \%$ & $5 \%$ & $12 \%$ & $24 \%$ & $43 \%$ \\
\hline 2 & Use of medicines daily? & $6 \%$ & $43 \%$ & $28 \%$ & $12 \%$ & $10 \%$ \\
\hline 3 & body temperature variations & $17 \%$ & $17 \%$ & $24 \%$ & $17 \%$ & $24 \%$ \\
\hline 4 & Feeling of dehydration & $17 \%$ & $19 \%$ & $26 \%$ & $22 \%$ & $16 \%$ \\
\hline 5 & Shortness of breath & $15 \%$ & $20 \%$ & $12 \%$ & $31 \%$ & $21 \%$ \\
\hline 6 & Chest pain & $20 \%$ & $9 \%$ & $7 \%$ & $26 \%$ & $29 \%$ \\
\hline 7 & Irregular heartbeat & $24 \%$ & $8 \%$ & $19 \%$ & $28 \%$ & $28 \%$ \\
\hline 8 & Hypersensitivity to food additives or other & $32 \%$ & $12 \%$ & $3 \%$ & $30 \%$ & $24 \%$ \\
\hline 9 & Insensitivity to heat/cold & $29 \%$ & $12 \%$ & $12 \%$ & $28 \%$ & $19 \%$ \\
\hline 10 & Increased Caffeine & $25 \%$ & $3 \%$ & $3 \%$ & $7 \%$ & $27 \%$ \\
\hline
\end{tabular}

Figure 1: Represents the ratio of chemical stress among type $1 \& 2$ diabetic patients

Ratio of Chemical stress among Type $1 \& 2$ Diabetes patients

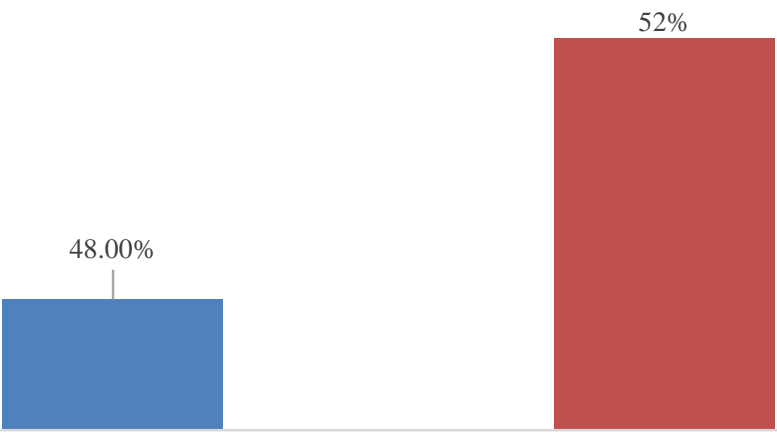

Type 1 Diabetes

Type 2 Diabetes

Figure 2: Represents the Ratio of both type $1 \& 2$ diabetic patients, in parameters of (Normal, Mild, Moderate \& Severe)

Ratio of Chemical Stress According to Sadaf Stress Scale SSS

33
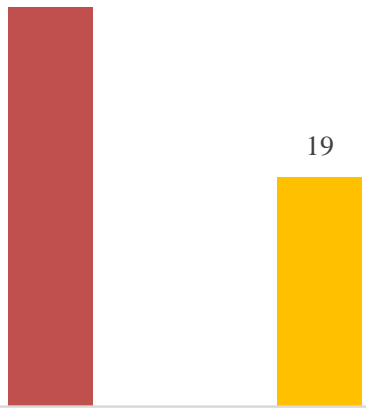

19

20

Normal

Mild

Moderate

Severe 


\section{Discussion}

Stress is the major trigger of diabetes which induces it by enhancing the blood glucose level by both physical and mental means. When the level of stress is high the stress hormones increase the blood sugar level and contributes to chronic hyperglycemia which has an effect on metabolic activity although it is an adaptive response in normal person but in diabetes due to lack of insulin the glucose cannot be metabolize properly hence induces many other problem. This study showed that $28 \%$ of diabetic patients were in severe chemical stress which could be due to medicine used for diabetes treatment. Due to lack of insulin and insulin resistance the stress related factor and triggers may contribute to induce cardiovascular, neuroendocrine, inflammatory and metabolic disorder in diabetic people the flight and fight response does not work well.

There is a doubled co-morbid risk for depression in diabetic as compared to normal healthy and hampering the normal life quality of patient. (Pouwer et al., 2003; Schram et al., 2009). In certain studies diabetic patient shows a considerable amount of high level of diabetic specific emotional stress (Pouwer et al., 2005; Kokoszka et al., 2009) physical activity increasing age and obesity has high prevelance rate in type 2 diabetic patients. (Wild et al., 2004).

However, the various symptoms of severity included body temperature $(50 \%)$, feeling of dehydration $(56 \%)$ and shortness of breath $(63 \%)$ that can cause severs oxidative stress. Oxidative stress is increased in metabolic syndrome and type 2 diabetes mellitus (T2DM) and this appears to underlie the development of cardiovascular disease, T2DM and diabetic complications. Increased oxidative stress appears to be a deleterious factor leading to insulin resistance, dyslipidemia, $\beta$-cell dysfunction, impaired glucose tolerance and ultimately leading to T2DM (Tangvarasittichai, 2015). As in the results chemical stress development is related to the patients with type 2 diabetes showing same factors that are also involved with oxidative stress. And as indicated by the symptoms like shortness of breath, feeling of dehydration can be coxidative alteration due to use of medications and altered glucose metabolism.

Many research studies demonstrated that T2DM patients have increased Reactive oxygen species (ROS) production-induced higher oxidative damage in the circulation and also have reduced antioxidant defenses mechanisms (Martín-Gallán P, 2003; Varvarovská J,2003; Seghrouchni I, 2002; VanderJagt DJ, 2001). Elevated free fatty acids, leptin and other circulating factors in T2DM patients may also contribute to cause ROS overproduction which leads to the development of oxidative stress. Oxidative stress plays the major role in the association with the insulin resistance pathogenesis by insulin signals disruption and adipocytokines dysregulation (Furukawa S, 2004; Houstis N, 2006) all these provide fuel specifically to the chemical stress.

\section{Conclusion}

It is concluded that the diabetes patient with type 2 diabetes are at higher risk of developing chemical stress that may indicate multiple metabolic and as indicated by prominent symptoms that can be a coxidative alterations on sequence of increase use of medications and altered glucose metabolism.

\section{Conflict of interes}

Authors declare no conflict of interest.

Acknowledgment

We would like to acknowledge Dr Sheshah Syed for assisting in data collection.
References

- Wild S, Roglic G, Green A, Sicree R, KingH. Global prevalence of diabetes: estimatesfor the year 2000 and projectionsfor 2030. Diabetes Care 2004;27:1047-1053

- Justin L. Rains and Sushil K. Jain, oxidative stress, insulin signaling, and diabetes, Free RadicBiol Med. 2011 March 1; 50(5): 567-575.

- International Diabetes Federation. IDF Diabetes Atlas update poster, 6th edn. Brussels, Belgium: International Diabetes Federation, 2014.

- Wright E, Jr JL. Scism-Bacon, and LC Glass. Oxidative stress in type 2 diabetes: the role of fasting and postprandial glycaemia. Int J ClinPract. 2006; 60:308-314. [PubMed: 16494646]

- West IC. Radicals and oxidative stress in diabetes. Diabetes Med. 2000;17:171-80.

- Sayed MR, Iman MM, Dawlat AS. Biochemical changes in experimental diabetes before and after treatment with mangiferaindica and psidium guava extracts. Int $\mathbf{J}$ Pharm Biomed Sci. 2011;2:29-41.

- Agnieszka P, Dorota R, Iren A, Maciej J, Stefan A. High glucose concentration affects the oxidantantioxidant balance in cultured mouse podocytes. J Cell Biochem. 2011;112:1661-72.

- Wolff SP. Diabetes mellitus and free radicals: free radicals, transition metals and oxidative stress in the aetiology of diabetes mellitus and complications. Br Med Bull. 1993;49:642.

- Giugliano D, Ceriello A, Paolisso G. Diabetes mellitus, hypertension and cardiovascular diseases: which role for oxidative stress? Metabolism. 1995;44:363-8.

- Sadaf, A. \& Shamoon, N. (2013). Sorts and Sources of Stress in Pakistan; A Comprehensive Outlook, International journal of endorsing health science research. (1), 1.

- Ozcan U, et al. Endoplasmic reticulum stress links obesity, insulin action, and type 2 diabetes. Science.2004;306:457-461.

- Nakatani Y, et al. Involvement of endoplasmic reticulum stress in insulin resistance and diabetes. J. Biol. Chem. 2005;280:847851

- Stress and Diabetes Mellitus richard s. Surwit, phdmark s. Schneider, phd

- Kahn SE, Cooper ME, Del Prato S (2014) Pathophysiology and treatment of type 2diabetes: Perspectives on the past, present, and future. Lancet 383(9922):1068-1083.2. Chrousos GP (2009) Stress and disorders of the stress system. Nat Rev Endocrinol5(7):374-381

- american Diabetes Association. Official Home Page of American Diabetes Association. 2007. How Stress Affects Diabetes. Retrieved on 14. 2. 2007 from

- http://www.diabetes.org/type-1-diabetes/stress.jsp

- Pouwer F, Beekman AT, Nijpels G, Dekker JM, Snoek FJ, Kostense PJ, Heine RJ, Deeg DJ. Rates and risks for co-morbid depression in patients with Type 2 diabetes mellitus: results from a community-based study. Diabetologia 46(7):892-898, 2003.

- Pouwer F, Skinner TC, Pibernik-Okanovic M, Beekman AT, Cradock S, Szabo S, Metelko Z, Snoek FJ. Serious diabetesspecific emotional problems and depression in a CroatianDutch-English Survey from the European Depression in Diabetes [EDID] Research Consortium. Diabetes Res ClinPract70(2):166-73, 2005.

- Kokoszka A, Pouwer F, Jodko A, Radzio R, Mućko P, Bieńkowska J, Kuligowska E, Smoczyńska O, Skłodowska Z. Serious diabetes-specific emotional problems in patients with type 2 diabetes who have different levels of comorbid depression: a Polish study from the European Depression in Diabetes (EDID) Research Consortium. Eur Psychiatry 24(7):425-430, 2009.

- Schram MT, Baan CA, Pouwer F. Depression and quality of life in patients with diabetes: a systematic review from the European 
depression in diabetes (EDID) research consortium. Curr Diabetes Rev5(2):112-119, 2009.

- Tangvarasittichai S. Oxidative stress, insulin resistance, dyslipidemia and type 2 diabetes mellitus. World J Diabetes 2015; 6(3): 456-480

- Martín-Gallán P, Carrascosa A, Gussinyé M, Domínguez C.Biomarkers of diabetes-associated oxidative stress and antioxidant status in young diabetic patients with or without subclinical complications. Free RadicBiol Med 2003; 34: 1563 1574.

- Varvarovská J, Racek J, Stozický F, Soucek J, Trefil L, Pomahacová R. Parameters of oxidative stress in children with Type 1 diabetes mellitus and their relatives. J Diabetes Complications 2003; 17: 7-10

- Seghrouchni I, Drai J, Bannier E, Rivière J, Calmard P, Garcia I, Orgiazzi J, Revol A. Oxidative stress parameters in type I, type II and insulin-treated type 2 diabetes mellitus; insulin treatment efficiency. ClinChimActa2002; 321: 89-96

- VanderJagt DJ, Harrison JM, Ratliff DM, Hunsaker LA, Vander Jagt DL. Oxidative stress indices in IDDM subjects with and WJD|www.wjgnet.com 474 April 15, 2015|Volume 6|Issue 3| Tangvarasittichai S. Oxidative stress and T2DM without longterm diabetic complications. ClinBiochem2001; 34:265-270

- Furukawa S, Fujita T, Shimabukuro M, Iwaki M, Yamada Y, Nakajima Y, Nakayama O, Makishima M, Matsuda M, Shimomura I. Increased oxidative stress in obesity and its impact on metabolic syndrome. J Clin Invest 2004; 114: 17521761

- Houstis N, Rosen ED, Lander ES. Reactive oxygen species have a causal role in multiple forms of insulin resistance. Nature 2006; 440: 944-948 